\title{
Personal, interpersonal and structural challenges to accessing HIV testing, treatment and care services among female sex workers, men who have sex with men and transgenders in Karnataka state, South India
}

\author{
Tara S H Beattie, ${ }^{1}$ Parinita Bhattacharjee, ${ }^{2}$ M Suresh, ${ }^{2}$ Shajy Isac, ${ }^{2}$ B M Ramesh, ${ }^{2,3}$ \\ Stephen Moses ${ }^{3,4}$
}

'Department of Global Health and Development, London School of Hygiene and Tropical Medicine, London, UK ${ }^{2}$ Karnataka Health Promotion Trust, Bangalore, Karnataka, India

${ }^{3}$ Department of Community Health Sciences, University of Manitoba, Winnipeg, Manitoba, Canada

${ }^{4}$ Department of Medical Microbiology, University of Manitoba, Winnipeg, Manitoba, Canada

\section{Correspondence to} Dr Tara S H Beattie, Department of Global Health and Development, London School of Hygiene and Tropical Medicine, 15-17 Tavistock Place, London WC1H 9SH, UK.

tara.beattie@|shtm.ac.uk

Accepted 26 January 2012 Published Online First 11 April 2012

\section{ABSTRACT \\ Background Despite high HIV prevalence rates among most-at-risk groups, utilisation of HIV testing, treatment and care services was relatively low in Karnataka prior to 2008. The authors aimed to understand the barriers to and identify potential solutions for improving HIV service utilisation. \\ Methods Focus group discussions were carried out among homogeneous groups of female sex workers, men who have sex with men and transgenders, and programme peer educators in six districts across Karnataka in March and April 2008.}

Results 26 focus group discussions were conducted, involving 302 participants. Participants had good knowledge about HIV and HIV voluntary counselling and testing (VCT) services, but awareness of other HIV services was low. The fear of the psychological impact of a positive HIV test result and the perceived repercussions of being seen accessing HIV services were key personal and interpersonal barriers to HIV service utilisation. Previous experiences of discrimination at government healthcare services, coupled with discriminatory attitudes and behaviours by VCT staff were key structural barriers to VCT service uptake among those who had not been HIV tested. Among those who had used government-managed prevention of parent to child transmission and antiretroviral treatment services, poor physical facilities, long waiting times, lack of available treatment, the need to give bribes to receive care and discriminatory attitudes of healthcare staff presented additional structural barriers.

Conclusions Embedding some HIV care services within existing programmes for vulnerable populations, as well as improving service quality at government facilities, are suggested to help overcome the multiple barriers to service utilisation. Increasing the uptake of HIV testing, treatment and care services is key to improving the quality and longevity of the lives of HIV-infected individuals.

\section{INTRODUCTION}

Early diagnosis and treatment of HIV-infected individuals is essential in promoting the long-term health and survival of people infected with HIV and can help prevent onward HIV transmission to sexual partners and infants of infected mothers. ${ }^{1}$ Despite the recent expansion of free antiretroviral treatment (ART) across the developing world, many HIV-positive individuals remain unaware of their status and do not benefit from ART. ${ }^{2}$ This is particularly true for some vulnerable populations, such as female sex workers (FSWs), and men who have sex with men and transgenders (MSM-T), where the limited numbers of studies available suggest that fewer than $20 \%$ have accessed voluntary counselling and testing (VCT) services. ${ }^{3}{ }^{4}$ The few qualitative studies conducted with FSWs and MSM-T suggest that a lack of knowledge about HIV/AIDS, VCT and ART, lack of perceived risk, anxieties about a positive test result, fears about being seen accessing HIV services, discrimination by healthcare providers and the fear of arrest may act as major disincentives to HIV testing. ${ }^{5-8}$ The 'double stigma' of an HIV-positive result, coupled with the potential disclosure of sex work and/or a stigmatised sexual orientation, can present additional barriers. ${ }^{5} 78$

India has an estimated 2.4 million people living with HIV. ${ }^{9}$ The HIV epidemic is highly heterogeneous, with the majority of infections occurring through heterosexual transmission. Unprotected paid sex is a major transmission route, particularly in the southern Indian states. Karnataka state in south India has an estimated adult HIV prevalence of $>1 \%$ in several districts and has the fourth highest HIV prevalence among the general population among Indian states. Karnataka has over 100000 FSWs and 25000 MSM-T, of whom approximately $17 \%$ are estimated to be infected with HIV. ${ }^{10-12}$

Sex work and same sex relationships are highly stigmatised within Indian society, and FSWs and men who have sex with men (MSM) frequently experience discrimination from their families, neighbours and even the state. ${ }^{5}{ }^{13}{ }^{14}$ MSM and hijras (transgenders) may or may not sell sex and may have sexual encounters either as a livelihood option or as an opportunity to assert or explore their sexuality. ${ }^{5}$ The Karnataka Health Promotion Trust (KHPT), supported by the India AIDS Initiative (Avahan) of the Bill and Melinda Gates Foundation, was established in December 2003 with the aim of developing and rapidly scaling up targeted interventions on HIV prevention among high-risk populations (FSWs, MSM and transgenders) in 18 of 27 districts in Karnataka. ${ }^{15}{ }^{16}$ As part of this process, dedicated sexually transmitted infection (STI) services for FSWs and MSM-T were established in every district, with these key populations (KPs) consulted on clinic locations and 
opening times and included in the recruitment and training of counsellors and medical staff. To reduce (conscious or unconscious) stigma and discrimination by clinical staff towards women who sell sex and MSM-T, it is important that they understand and accept the sexuality and the work of the FSW and MSM-T communities. To facilitate this, staff employed by such STI services receive classroom as well as experiential training through dialogues and exposure to KPs. In addition, STI clinic committees, headed by FSWs and MSM-T, were established in each district, providing a forum where any grievances towards clinical services could be aired and re-dressed. Due to the non-availability of affordable HIV care and support services when the HIV prevention programmes were originally implemented (2003-2004), HIV testing was not actively promoted initially.

However, since 2006, there has been an exponential increase in government-funded HIV care and support services throughout India in response to the escalating HIV epidemic, with the number of ART centres offering free HIV treatment increasing from 40 to 292 between 2006 and $2010 .{ }^{17}{ }^{18}$ In response, the HIV prevention programmes began promoting improved access to VCT and HIV care services as part of efforts to improve health and well-being among FSWs and MSM-T. However, despite high HIV prevalence rates among FSWs $(16.3 \%)^{11}$ and MSM-T $(17.6 \%),{ }^{10}$ utilisation of free government HIV services by these populations in Karnataka was initially low, with only $28 \%$ of FSWs reporting ever having been tested for HIV in 2005-2007. ${ }^{19}$ This qualitative study was conducted as a needs assessment within the context of the Avahan programme to understand the barriers to accessing HIV care services across different typologies of FSWs and MSM-T and to identify strategies to overcome them.

\section{MATERIALS AND METHODS Study population and recruitment}

Focus group discussions (FGDs) were conducted with homogeneous groups of 6-15 FSWs, MSM-T and peer educators in six districts across Karnataka in March and April 2008. The districts were selected purposively to represent different geographic regions across the state (north, Belgaum; south, Bangalore; east, Bellary; west, Davangere; central, Hubli and Dharwad). Participants were recruited purposively, with the help of the local implementing non-governmental organisations (NGOs), and witnessed verbal informed consent was obtained from each participant before each focus group. FSWs, MSM and peer educators were interviewed in each district, with 8-15 participants recruited for each focus group. The number of FGDs conducted with FSWs, MSM and peer educators was decided based on the proportion of the total population of these groups in each district. FSWs were selected based on the predominant typology of FSW present in that district (street-, brothel- or home-based). Where two or more typologies were present in equal numbers, FGDs were conducted with each typology. In addition, in districts where women sold sex in both rural and urban areas, FGDs were conducted with both rural and urban FSWs. Transgenders were interviewed in Bangalore only, where there are relatively high numbers from this community.

\section{FGDs and analysis}

Each FGD was led by a trained facilitator in the local language, Kannada, who followed guidelines developed for this study. Facilitator's had postgraduate qualifications in social sciences, were fluent in the local language and had a minimum of 3 years experience in collecting qualitative data for similar projects. Prior to the study, they received training by KHPT in FGD facilitation and data recording and were supported by senior staff during the period of data collection.

Focus groups discussed knowledge around HIV transmission routes; perception of own/community to risk of HIV; benefits and drawbacks to knowing one's own HIV status; and experiences, barriers and suggestions to utilizing VCT, prevention of parent to child transmission (PPTCT), HIV care and support, and ART services. Interviews were tape-recorded, transcribed, translated into English and analysed for persistent themes and ideas.

\section{RESULTS}

\section{Study population}

Three hundred and two individuals participated in 26 FGDs Their group categories, mean age and age range, typology, district and number per group are shown in table 1. Eleven FGDs were held with 125 FSWs; five FGDs with 56 MSM (kothis and double-deckers) and one FGD with six transgenders (hijras). Kothis are effeminate men who may cross-dress but remain biologically male; double-deckers are primarily sexually oriented towards men, but their gender identity is more masculine or neutral than kothi. Hijras are male-to-female transgenders who may or may not be castrated. ${ }^{20}$ In addition, seven FGDs were held with 87 female peer educators and two focus groups with 28 male peer educators (table 1). The mean age of participants was 30.5 years (range $18-59$ years), and all KPs were registered with the local implementing NGO HIV prevention partner.

\section{Personal factors influencing HIV service utilisation}

Most participants had comprehensive knowledge about HIV and had accurate perceptions of their vulnerability to HIV infection. Several examples were cited of situations where a condom may not be worn and community members may be exposed to infection: unprotected sex for increased payment, trusting a regular partner or spouse, rape, client secretly tearing or removing a condom during sex, condom breakage during anal sex, alcohol use reducing impetus to use a condom and unprotected sex for increased sexual pleasure.

The fear of the impact of a positive HIV result on an individual's mental health presented a major barrier to FSWs and MSM-T accessing VCT services (table 2), with respondents underlining how serious this issue was with several examples of individuals contemplating or committing suicide after learning about their positive status. As a result of this fear, some reported going for testing, but not returning for their results, while others were in denial that they could be HIV positive, as they did not have any symptoms to suggest that they were unwell. Several explained that community members would prefer to remain ignorant of their HIV status rather than face the knowledge that they were HIV positive:

Many people resort to their fate and decide to live as long as their fate permits them and one day die quietly. Everyone has to die one day, no one can escape. This is the kind of philosophy they follow. (Female peer educator, Hubli)

In addition, although most groups knew about VCT services and where they could access them, some participants mistakenly thought that the STI tests carried out at the NGO clinic included HIV testing. Furthermore, few participants (mainly peer educators) had information or experience of 
Table 1 Socio-demographic characteristics of FGD participants

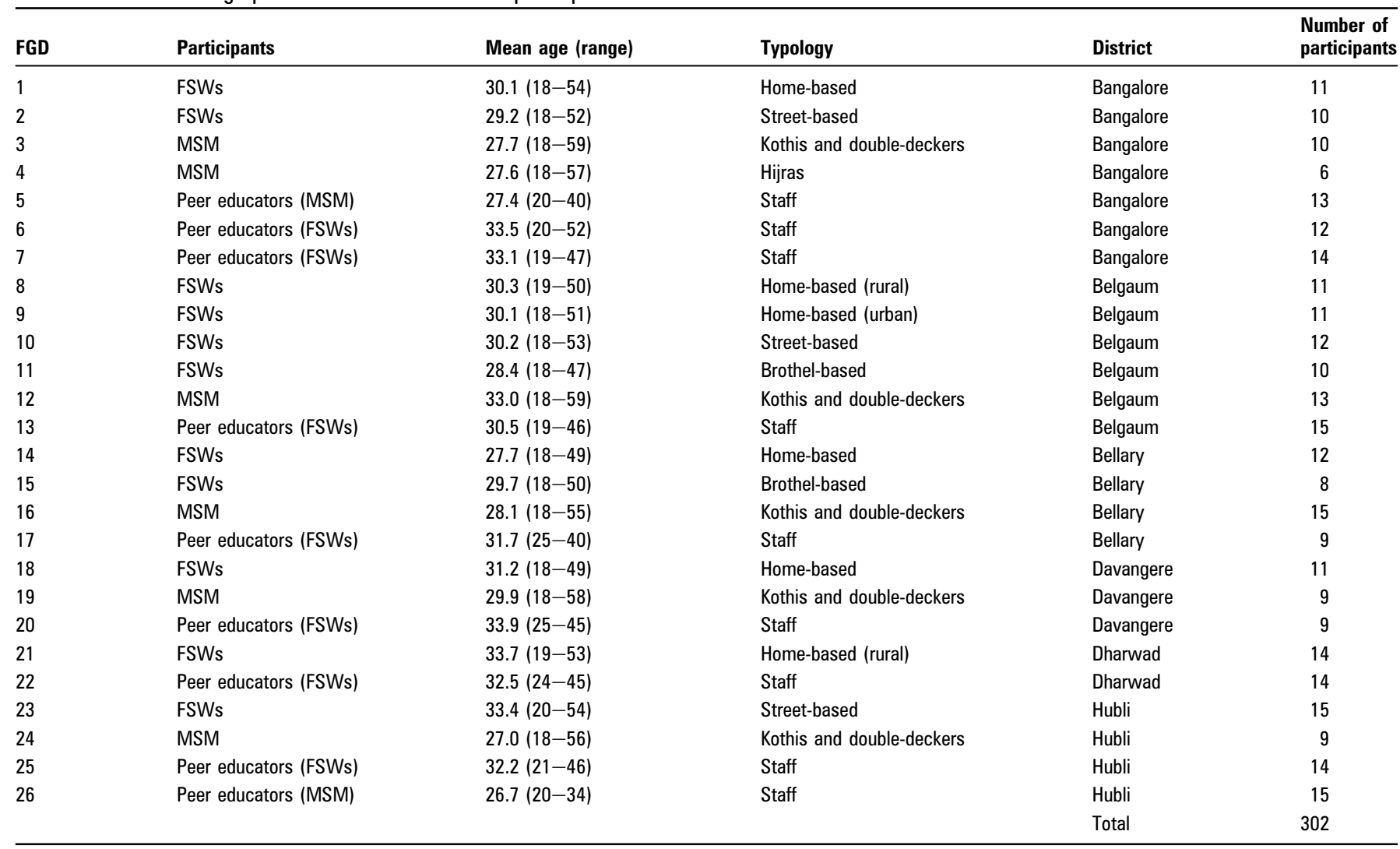

FGD, focus group discussions; FSWs, female sex workers; MSM, men who have sex with men.

PPTCT, ART or HIV care and support services. This lack of knowledge about the existence of HIV services presented another key personal barrier to FSWs and MSM-T accessing them (table 2).

Among those FSWs and MSM-Twho had been tested for HIV, the main personal motivator was understanding the benefits of knowing one's status, including improving the quality and longevity of their lives by taking care of their health and using ART (table 2). This was particularly important for FSWs with young children:

Some women show concern for their children. They fear their death to bring misery to their children. They want to live longer for the sake of their children. With that sense of responsibility they go get tested for HIV. (Street-based FSW, Bangalore)
In the event of a negative test result, participants described the relief of knowing one's negative status and their strengthened resolve to resist unprotected intercourse in the future.

\section{Interpersonal factors influencing HIV service utilisation}

The main interpersonal barrier to FSWs and MSM-T accessing HIV testing and treatment services was the pervading fear of discrimination from families, neighbours, landlords, schools and others following inadvertent disclosure of sex work, homosexuality and/or an HIV-positive status. Many participants had either witnessed or experienced sex work, MSM-T or HIV-related discrimination, including being physically abused or abandoned by husbands and families; being made destitute, being 'taunted' or 'looked down upon' by neighbours; people living with HIV/

Table 2 Summary of the key personal, interpersonal and structural factors influencing HIV service uptake by FSWs, MSM and transgenders in Karnataka state

\begin{tabular}{|c|c|c|}
\hline & Barriers & Motivators \\
\hline Personal & $\begin{array}{l}\text { Lack of knowledge about HIV services; denial of HIV risk/fatalism; } \\
\text { fear of mental health impact of a positive test result }\end{array}$ & Clear understanding of the benefits of knowing one's status \\
\hline Interpersonal & $\begin{array}{l}\text { Fear of discrimination by family, neighbours, schools and government } \\
\text { officials following inadvertent disclosure of sex work, homosexuality } \\
\text { and/or HIV infection }\end{array}$ & None provided \\
\hline \multicolumn{3}{|l|}{ Structural } \\
\hline Quality of care & $\begin{array}{l}\text { Discrimination and homophobia; derogatory comments; denial of treatment; } \\
\text { diagnosing without examination; ineffective treatment; poor facilities } \\
\text { at PPTCT service points }\end{array}$ & $\begin{array}{l}\text { Empathetic and caring staff, with a good understanding of } \\
\text { issues facing the FSW/MSM-T community; NGOs challenging } \\
\text { discriminatory behaviour and bribes }\end{array}$ \\
\hline Confidentiality & $\begin{array}{l}\text { Location within hospitals; queuing for HIV services in } \\
\text { hospital corridors; counselling facilities at VCT centres }\end{array}$ & Services located in non-public settings (eg, NGO STI clinics) \\
\hline Access & $\begin{array}{l}\text { Long distances; charges for 'free' services; long waiting times; quotas } \\
\text { at ART centres; ID cards and ration cards; a 'buddy' to access ART services }\end{array}$ & $\begin{array}{l}\text { FSW/MSM-T 'exclusive' services; peer educators accompanying } \\
\text { community members to services }\end{array}$ \\
\hline
\end{tabular}

ART, antiretroviral treatment; FSW, female sex worker; MSM-T, men who have sex with men and transgenders; NGO, non-governmental organisation; PPTCT, prevention of parent to child transmission; STI, sexually transmitted infection; VCT, voluntary counselling and testing. 
AIDS (PLWHAs) being locked in cages or sheds in villages until they died; nobody conducting the last rites following the death of an HIV-positive person; landlords refusing to rent their houses; and children of positive sex workers being disallowed admission by schools:

There was this woman who had visited Bombay for a while. She had HIV... Doctor advised her family to take good care of her. But, her family did not take care of her well. After they learned she had HIV, they kept her away in a farm house in their field. Then they shifted her to a shed where waste was dumped. They were not feeding her properly. She ultimately died there. (Brothel-based FSW, Belgaum)

MSM-T were also fearful that if they underwent HIV testing and were found to be HIV positive, they would experience discrimination from within the MSM-T community:

If someone is HIV positive, even our own people move away from them. Our own community members do like that. That is why for the fear of disclosure none of us dare to get tested. (Hijras, Bangalore)

For rural women, as babies are traditionally delivered by village elders at home, choosing to give birth in a hospital setting (in order to receive nevirapine) would invoke intense scrutiny and risked arousing suspicion, both of their sex work and their HIV-positive status:

Those people living with HIV, for the fear of husband and in-laws coming to know about their status, prefer to have the delivery conducted at home. (Female peer educator, Davangere)

\section{Structural factors influencing HIV service utilisation Perceived quality of care}

Discriminatory attitudes of staff working at government healthcare facilities, especially towards those who are sex workers, from sexual minorities and/or who are HIV positive, were the major demotivators to FSWs and MSM-T accessing HIV services. Discrimination and homophobia were elaborated in terms of derogatory comments made by service providers; little understanding among service providers about sex work and sexuality; assumptions by service providers that participants were HIV positive because they sell sex; refusal by service providers to treat patients, including sending patients to the back of the queue or to different hospitals, prescribing medication without conducting a medical examination and prescribing ineffective treatment:

On our visit to a VCT, they treat us like garbage. They ask us to queue up, stand here, stand there... We feel bad about this. We thoroughly regret going there. We prefer to die than to get insulted like this. They treat women in sex work with insult and discrimination. (Female peer educator, Hubli)

Among those FSWs and MSM-T who had not accessed VCT services, experiences of discrimination at other government healthcare facilities were a key structural barrier to accessing HIV services. However, although actual discrimination against FSWs was reported at ART centres and some PPTCT services, this was not true for most VCT or care and support centres, where there were several reports of kind sensitive counsellors and medical staff. Thus, the fear of discrimination by FSWs was not always realised in practice, especially at VCT services. However, among MSM-T who had accessed HIV VCT, ART and other treatment and care services, homophobia and discrimination were again reported:
I have a fear that people may taunt me for having a 'womanly' feeling. When I went to a government hospital, they discriminated against me. They looked down on me. Made me stand and wait here and there. Made me stand in the queue till all others are attended to. With all this suffering, when I ultimately went inside, there also they taunted me, looked down on me. I felt very bad. I terribly regretted for having gone there. (Male peer educator, Hubli)

Although questions on NGO-run STI services were not included in the FGD guidelines, a clear unexpected outcome that emerged was community members' high regard for the NGO services. In particular, participants reported trusting the staff and the services provided by the NGO STI clinics and valued the 'exclusivity' provided by these services. They felt comfortable to disclose that they were sex workers and were confident that consultations between the doctors at the NGO clinics and themselves would remain confidential:

If we undergo testing in our organization, the matter remains confidential and it is done free. It is not the same in government hospital, so we undergo test here only. (MSM, Davangere)

When staff were sensitised towards FSWs and MSM-T, either because they worked as clinical staff at the NGO STI clinic or because they had visited the project centres to learn about these communities, participants reported feeling comfortable to discuss their sexuality and their medical problems and motivated to access HIV and STI services:

Though the services in government hospital are also almost free, we are not able to openly speak about our problems. But here we are comfortable in talking to our doctor. They patiently listen to us (Home-based FSW, Bangalore)

We don't consult outside. Because, I don't know how to express the fact that I am MSM. That is why I don't go. Whereas in our clinic, there are people known to us, we can freely share our problems with them... (MSM, Hubli)

\section{Confidentiality}

Another structural barrier to FSWs and MSM-T accessing HIV services involved concerns around maintaining confidentiality, both when accessing HIV services located within hospital settings (where they may be seen by a family member or neighbour) and during VCT sessions held in chambers, which could be overheard by people in the waiting room. Maintaining confidentiality was particularly problematic at ART centres, where patients had to queue for several hours underneath signs for 'HIV-positive people':

Only ___ knows that I am positive. I would have disclosed my positive status only to him. It is not public. But when I go there and wait in the queue, that I am HIV positive is made public. Everyone knows it. All of them standing in the queue in the ART Centre are positive only. It is certain that they have come to receive ART treatment. It has become very difficult to receive ART treatment. (MSM, Bangalore)

\section{Barriers to service utilisation}

Key barriers to utilisation of HIV services reported by FSWs and MSM-T, included having to travel long distances to access services, costs associated with travel and with bribes for 'free' services, loss of earnings when not selling sex and the requirements for ration and ID (identity) cards (which are often not available to these populations) to receive treatment. In addition, ART services were reported to be overstretched and underresourced, with monthly ART quotas and ART drug rationing by staff, shortages of CD4 testing facilities and long waiting 
times lasting several days. ART services also required patients to present ID and ration cards and to take a 'buddy' or family member (to help with adherence) before they would issue treatment, effectively prohibiting many community members from accessing treatment:

One of the patients had come from another district. They were very serious. When they went there [the ART centre] the first day, they were sent back as the time of consultation was up. They said they attend only for one and a half hours and asked them come during that timing. The patient is not able even stand, impossible to hold him also. He was crying like anything. Counselling was done. It did not go well. Counsellor's style was unsuitable for him, he was crying. Finally, they said that ART has to be given. Then they asked for the ration card. This person said, I don't have a ration card and I am from Bellary. The moment they came to know that the person is from Bellary, they said, there is an ART centre in Bellary itself. Districts have quotas. Here treatment quota is available only to those who belong to Dharwad district, Bellary people don't have a quota here. You go to Bellary hospital, they give ART treatment there only. (Male peer educator, Hubli)

Among some brothel-based FSWs who felt unsafe leaving the confines of their brothel, the threat of physical or sexual abuse by 'rowdies' or gangs presented additional barriers to service utilisation.

NGO peer educators were reported to use various strategies to overcome barriers to service utilisation, including providing emotional and practical support by accompanying community members to HIV services and paying their transport costs. Some NGOs had successfully advocated with government HIV treatment and care services, resulting in positive changes to staff attitudes and the removal of charges for 'free' services:

Last time I have warned them. I told them if you treat us like this again I am going to write to Bangalore. After such encounter, now whenever they see me, they ask me to come up and ask who I have brought with me. They respect me now. (Female peer educator, Hubli)

\section{DISCUSSION}

The recent scale-up of HIV testing, treatment and care services across many regions of the developing world aims to increase the longevity and quality of the lives of PLWHAs and also forms a key strategy for HIV prevention. ${ }^{2}{ }^{21}$ However, despite great HIV treatment and care needs, FSWs, MSM and transgender communities underuse these services for a variety of reasons, including the fear associated with a positive test result and fears of HIV-related discrimination and recrimination by family, neighbours, healthcare providers and the state. ${ }^{3-822}$ The results of our study in Karnataka suggest that multiple personal, interpersonal (community) and structural (service provider) factors influence HIV service utilisation by this population and will need to be addressed if uptake of HIV testing, care and support services is to improve.

Unlike elsewhere, FSWs and MSM-T in our study had comprehensive knowledge of HIV transmission routes and accurate perceptions of their communities' elevated risk of infection. ${ }^{67}$ In addition, many knew about VCT services. A lack of knowledge about ART, care and support and PPTCT services, coupled with the fear of a positive test result, were the major personal barriers to HIV service use. Educating peer educators more fully about HIV services is required, so that this information can be communicated to their peers. In addition, as indicated by some participants in our study, developing a clear understanding of the benefits of early HIV diagnosis may help individuals overcome the fear of being tested for HIV.
The main interpersonal barrier to HIV service utilisation by FSWs and MSM-Twas the fear of reprisals by family, neighbours and the wider community. Given the significant societal discrimination against sex work, sexual minorities and PLWHAs, 1578131423 the unwillingness of FSWs, MSM and transgenders to access services and undergo HIV testing is not surprising. Similar to elsewhere, for participants in our study, accessing these services in hospital settings risked the double stigma of being exposed as a sex worker/MSM-T and as someone infected with HIV. ${ }^{5} 8$ Developing dedicated HIV testing services for FSWs, MSM and transgender populations within existing NGO-operated STI services, which are located away from hospital settings in sites selected by the community, could help overcome fears of being seen accessing these services. ${ }^{24}$ Furthermore, the entrenched societal prejudices held against these communities need to be addressed, for example, through education, awareness and sensitisation campaigns aimed at the whole community, and by changes in attitudes that discriminate against individuals based on their occupation, sexual orientation or HIV status. ${ }^{5}$ To this end, the KHPT has been working in collaboration with state and local government and police forces to advocate for policy changes to prohibit sex worker-associated violence and discrimination, and with journalists to address societal stigma by changing the ways in which the media report on these issues. ${ }^{25-27}$

Experiences of FSW, MSM-T and HIV-related discrimination at government-run healthcare services were common and served as a powerful structural barrier to accessing government-run HIV services. Similar experiences have been described across Asia. ${ }^{5-8} 1314$ Clearly, staff training programmes to develop better understanding and acceptance towards stigmatised communities such as MSM-T and FSWs and policies prohibiting the discrimination of patients based on their occupation or sexuality are needed. ${ }^{1}{ }^{27}$ Indeed, when clinical staff had been exposed to these communities through training programmes designed and facilitated by FSWs and MSM-T, either because they worked in the NGO STI clinics or because they had visited the NGO projects to learn more about the community, kind, respectful and non-judgemental attitudes were reported by study participants, who said that they felt comfortable talking to such staff about their problems.

Several structural barriers to service access also contributed to low HIV service uptake, and these can be dealt with in different ways. Some NGO peer educators help community members overcome cost, distance and waiting time barriers by accompanying them to the various HIV services. Elsewhere, the provision of mobile VCT services have proved popular with some hard-to-reach groups and would likely be welcomed by brothel-based FSWs, who requested additional support in accessing VCT. ${ }^{28} 29$ Innovative strategies, such as the administration of nevirapine during home births, are also required to enable pregnant FSWs in rural villages to access PPTCT services.

Government ART services were reported by FSWs and MSM-T to be overstretched and under-resourced, with the demand for these free services evidently high. Ensuring that government ART services have the resources to cope with demand is vital to reduce the morbidity and mortality of PLWHAs. Furthermore, current HIV service policies that require ID cards, ration cards and a 'buddy' effectively prohibit many $\mathrm{KP}$ members from accessing ART and other HIV services and need to be addressed. Although the 'buddy' system was introduced by ART services to help with adherence, it has not worked well among the FSW and MSM-T communities as these populations 


\section{What is already known on this subject}

- There is a paucity of data examining the barriers to uptake of VCT and of HIV care and treatment services by FSWs and MSM-T in developing countries

- Stigma is known to be a significant barrier, but it is unclear how this affects access to HIV services by FSWs and MSM-T.

- This study was conducted to understand the factors contributing to the low uptake of government-run HIV testing, treatment and care services by this population in Karnataka state, South India.

\section{What this study adds}

- Personal, interpersonal and structural barriers were identified, which prevent many sex workers from accessing governmentmanaged HIV services.

- These barriers did not exist for NGO-run STI services dedicated to sex workers.

- We suggest embedding HIV testing services within dedicated clinics for FSWs and MSM-T and improving service quality at government HIV treatment and care facilities to help overcome the multiple barriers to service utilisation.

are already highly marginalised and are reluctant to disclose their HIV-positive status to anyone for fear of additional stigma and loss of business. Strategies to destigmatise HIV-positive sex workers are needed if a 'buddy' system is to help rather than hinder access to ART among these communities. In addition, training HIV-positive peer educators to act as role models to motivate their community members to access HIV services may help to destigmatise HIV infection among the FSW and MSM-T communities.

This study had several limitations. The purposive selection of districts, to include different geographic regions across the state, and the purposive selection of study participants by the NGOs, means that the study population may not be representative of the FSW/MSM-T population as a whole. However, the consistency of reporting of the key themes emerging from the study across focus groups and districts suggests that this is unlikely. In addition, transgenders were selected from Bangalore only, and as such their views were likely under-represented. Finally, with a sensitive topic such as HIV, reporting bias may have resulted in the under-reporting of unfavourable experiences at HIV services, particularly because participants were interviewed in groups instead of individually.

In conclusion, multiple personal, interpersonal and structural barriers prevent utilisation of HIV services by FSWs and MSM-T. Overcoming these barriers will require a multifaceted approach, involving FSWs, MSM-T, local communities, service providers and policy-makers. Continued education of these vulnerable populations and their families and communities on HIV transmission and prevention and HIV testing and treatment services, as well as on the benefits of early HIV diagnosis, is necessary to overcome personal barriers to accessing services. Dedicated sex worker HIV testing services provided as part of the standard package of care by NGO-led STI clinics could help to overcome the interpersonal and structural barriers to accessing testing services. Facilitating access to HIV testing and treatment services is crucial in enabling PLWHA to claim their right to good health and also to enhance HIV prevention.

Acknowledgements We thank the female sex worker, MSM and transgender populations throughout Karnataka with whom we work, and the staff members of the programme implementing NGOs, for their tireless work in enhancing HIV prevention programming. In particular, we thank the following NGOs: BIRDS, MYRADA, SPAD, Bhoruka Charitable Trust, Action Aid, Swati Mahila Sangha, Swast and Sangama; and the following regional managers: Raghavendra T, Dhanunjaya Rao, Usha Rani, Bharat Shetti and M Baburaj.

Contributors TSHB designed the study, performed the analyses and wrote the first draft of the paper. PB designed the study and contributed to writing the paper. MS designed and oversaw local implementation of the study. BMR and SI designed and supervised the study. SM designed the study and contributed to writing the paper.

Funding Support for this study was provided by the Bill and Melinda Gates Foundation. The views expressed herein are those of the authors and do not necessarily reflect the official policy or position of the Bill and Melinda Gates Foundation.

\section{Competing interests None.}

Ethics approval Ethical approval for this study was granted by the Institutional Review Board of St. John's Medical College and Hospital in Bangalore, India.

Provenance and peer review Commissioned; externally peer reviewed.

\section{REFERENCES}

1. Obermeyer CM, Osborn M. The utilization of testing and counseling for HIV: a review of the social and behavioral evidence. Am J Public Health 2007;97:1762-74.

2. Matovu JK, Makumbi FE. Expanding access to voluntary HIV counselling and testing in sub-Saharan Africa: alternative approaches for improving uptake, 2001-2007. Trop Med Int Health 2007:12:1315-22.

3. Dandona R, Dandona L, Kumar GA, et al. HIV testing among female sex workers in Andhra Pradesh, India. AIDS 2005;19:2033-6.

4. Xu J, Brown K, Ding G, et al. Factors associated with HIV testing history and HIV-test result follow-up among female sex workers in two cities in Yunnan, China. Sex Transm Dis 2011;38:89-95.

5. Chakrapani V, Newman PA, Shunmugam M, et al. Structural violence against Kothiidentified men who have sex with men in Chennai, India: a qualitative investigation. AIDS Educ Prev 2007;19:346-64.

6. Ngo AD, Ratliff EA, McCurdy SA, et al. Health-seeking behaviour for sexually transmitted infections and HIV testing among female sex workers in Vietnam. AIDS Care 2007;19:878-87.

7. Wang Y, Li B, Zheng J, et al. Factors related to female sex workers' willingness to utilize VCT service: a qualitative study in Jinan City, Northern China. AIDS Behav 2009;13:866-72.

8. Chakrapani V, Newman PA, Shunmugam M, et al. Barriers to free antiretroviral treatment access for female sex workers in Chennai, India. AIDS Patient Care STDS 2009;23:973-80.

9. UNAIDS. UNAIDS Report on the Global AIDS Epidemic. 2010. http://www.unaids. org/globalreport/documents/20101123_GlobalReport_full_en.pdf laccessed 9 Dec 2011).

10. National AIDS Control Organisation (NACO). HIV Sentinel Surveillance and HIV Estimation In India 2007. A Technical Brief. New Delhi: NACO, 2008. https://www. nacoonline.org/upload/Publication/MqE\%20Surveillance\%20Research/HIV\% 20Sentine|\%20Surveillance\%20and\%20HIV\%20Estimation\%202007_A\%20Technical \%20Brief.pdf (accessed 4 Jan 2009).

11. Ramesh BM, Moses S, Washington R, et al. Determinants of HIV prevalence among female sex workers in four south Indian states: analysis of cross-sectional surveys in twenty-three districts. AIDS 2008;22(Suppl 5):S35-44.

12. World Health Organisation. HIVIAIDS Among Men Who Have Sex With Men and Transgender Populations in South-East Asia. The Current Situation and National Responses. 2010. http://www.searo.who.int/LinkFiles/Publications_MSM-combined. pdf (accessed 9 Dec 2011).

13. Elamon J. A situational analysis of HIV/AIDS-related discrimination in Kerala, India AIDS Care 2005;17(Suppl 2):S141-51.

14. Paxton S, Gonzales G, Uppakaew K, et al. AIDS-related discrimination in Asia. AIDS Care 2005;17:413-24.

15. Avahan. Avahan - the India AIDS Initiative: The Business of HIV Prevention at Scale New Delhi: The Bill \& Melinda Gates Foundation. 2008. http://www.gatesfoundation. org/avahan/Documents/Avahan_HIVPrevention.pdf (accessed 4 Jan 2010).

16. Reza-Paul S, Beattie T, Syed $\bar{H} U$, et al. Declines in risk behaviour and sexually transmitted infection prevalence following a community-led HIV preventive intervention among female sex workers in Mysore, India. AIDS 2008;22(Suppl 5): s $91-100$. 
17. National AIDS Control organisation (NACO). Annual Report 2008-09. 2009 http://www.nacoonline.org/Quick_Links/Publication/Annual_Report/ NACO Annual Report/ (accessed 8 Dec 2011)

18. National AIDS Control organisation (NACO). NACO Annual Report 2011. 2011 http://www.nacoonline.org/upload/REPORTS/NACO\%20Annual\%20Report\%20201011.pdf (accessed 8 Dec 2011)

19. Indian Council of Medical Research and Family Health International. National Interim Summary report, integrated Behavioural and Biological assessment (IBBA), Round 1 (2005-2007). New Delhi, 2007. http://www.nari-icmr.res.in//BBA/BBBANISR.pdf (accessed 8 Dec 2011).

20. Phillips $\mathbf{A E}$, Boily MC, Lowndes $\mathrm{CM}$, et al. Sexual identity and its contribution to MSM risk behavior in Bangaluru (Bangalore), India: the results of a two-stage cluster sampling survey. J LGBT Health Res 2008;4:111-26.

21. WHO, UNAIDS, UNICEF. Towards Universal Access: Scaling Up Priority HIVIAIDS Interventions in the Health Sector. Progess Report. 2010. http://www.hoint/hiv/pub/ 2010progressreport/report/en/indexhtml (accessed 30 Aug 2011).

22. Wang $\mathbf{Y}$, Pan JB, Wang XF, et al. Reported willingness and associated factors related to utilization of voluntary counseling and testing services by female sex workers in Shandong Province, China. Biomed Environ Sci 2010;23:466-72.
23. Meiberg AE, Bos AE, Onya $\mathrm{HE}$, et al. Fear of stigmatization as barrier to voluntary HIV counselling and testing in South Africa. East Afr J Public Health 2008;5:49-54.

24. Lafort Y, Geelhoed D, Cumba L, et al. Reproductive health services for populations at high risk of HIV: Performance of a night clinic in Tete province, Mozambique. BMC Health Serv Res 2010;10:144.

25. Dhanaraj G, Gurnani V. Developing an Enabling Environment and Reducing Vulnerabilities of Key Population in a HIV Prevention Programme. Bangalore, India: Karnataka Health Promotion Trust, 2006

26. Beattie TS, Bhattacharjee P, Ramesh BM, et al. Violence against female sex workers in Karnataka state, south India: impact on health, and reductions in violence following an intervention program. BMC Public Health 2010;10:476.

27. Gurnani V, Beattie TS, Bhattacharjee P, et al. An integrated structural intervention to reduce vulnerability to HIV and sexually transmitted infections among female sex workers in Karnataka state, south India. BMC Public Health 2011;11:755.

28. Ellen JM, Bonu S, Arruda JS, et al. Comparison of clients of a mobile health van and a traditional STD clinic. J Acquir Immune Defic Syndr 2003;32:388-93.

29. Morin SF, Khumalo-Sakutukwa G, Charlebois ED, et al. Removing barriers to knowing HIV status: same-day mobile HIV testing in Zimbabwe. J Acquir Immune Defic Syndr 2006;41:218-24. 